\title{
Reproductive phenology across the lunar cycle: parental decisions, offspring responses, and consequences for reef fish
}

\author{
Jeffrey S. Shima (D) ${ }^{1,6}$ Craig W. Osenberg (iD), ${ }^{2}$ Suzanne H. Alonzo, ${ }^{3}$ Erik G. Noonburg, ${ }^{4}$ \\ Pauline Mitterwallner, ${ }^{1}$ and Stephen E. Swearer ${ }^{2}{ }^{5}$ \\ ${ }^{1}$ School of Biological Sciences, Victoria University of Wellington, Wellington 6140 New Zealand \\ ${ }^{2}$ Odum School of Ecology, University of Georgia, 140 East Green Street, Athens, Georgia 30602 USA \\ ${ }^{3}$ Department of Ecology and Evolutionary Biology, University of California at Santa Cruz, Santa Cruz, California, USA \\ ${ }^{4}$ Biological Sciences, Florida Atlantic University, Davie, Florida 33314 USA \\ ${ }^{5}$ School of Biosciences, University of Melbourne, Melbourne, Victoria 3010 Australia
}

Citation: Shima, J. S., C. W. Osenberg, S. H. Alonzo, E. G. Noonburg, P. Mitterwallner, and S. E. Swearer. 2020. Reproductive phenology across the lunar cycle: parental decisions, offspring responses, and consequences for reef fish. Ecology 101(8):e03086. 10.1002/ecy.3086

Abstract. Most organisms reproduce in a dynamic environment, and life-history theory predicts that this can favor the evolution of strategies that capitalize on good times and avoid bad times. When offspring experience these environmental changes, fitness can depend strongly upon environmental conditions at birth and at later life stages. Consequently, fitness will be influenced by the reproductive decisions of parents (i.e., birth date effects) and developmental decisions (e.g., adaptive plasticity) of their offspring. We explored the consequences of these decisions using a highly iteroparous coral reef fish (the sixbar wrasse, Thalassoma hardwicke) and in a system where both parental and offspring environments vary with the lunar cycle. We tested the hypotheses that (1) reproductive patterns and offspring survival vary across the lunar cycle and (2) offspring exhibit adaptive plasticity in development time. We evaluated temporal variation in egg production from February to June 2017, and corresponding larval developmental histories (inferred from otolith microstructure) of successful settlers and surviving juveniles that were spawned during that same period. We documented lunar-cyclic variation in egg production (most eggs were spawned at the new moon). This pattern was at odds with the distribution of birth dates of settlers and surviving juveniles-most individuals that successfully survived to settlement and older stages were born during the full moon. Consequently, the probability of survival across the larval stage was greatest for offspring born close to the full moon, when egg production was at its lowest. Offspring also exhibited plasticity in developmental duration, adjusting their age at settlement to settle during darker portions of the lunar cycle than expected given their birth date. Offspring born near the new moon tended to be older and larger at settlement, and these traits conveyed a strong fitness advantage (i.e., a carryover effect) through to adulthood. We speculate that these effects (1) are shaped by a dynamic landscape of risk and reward determined by moonlight, which differentially influences adults and offspring, and (2) can explain the evolution of extreme iteroparity in sixbars.

Key words: adaptive plasticity; carryover effect; coral reef fish; ecoevolutionary feedback; life history; lunar periodicity; otolith microstructure; recruitment; reproductive output; seasonality; selection; settlement.

\section{INTRODUCTION}

Most organisms live in a dynamic environment, where environmental conditions (e.g., food, shelter, predators) vary through time (Fretwell 1972). This implies a series of "good" and "bad" times for activities such as foraging, migration, and reproduction. Temporal variation in the environment contributes to variation in demographic rates, which affects population dynamics (Reid et al. 2018) and can influence the evolution of life-history

Manuscript received 13 December 2019; revised 19 March 2020; accepted 1 April 2020. Corresponding Editor: Lorenzo Ciannelli.

${ }^{6}$ E-mail: jeffrey.shima@vuw.ac.nz traits (e.g., when and where to reproduce; Johannes 1978, Thomas et al. 2001). Even when components of environmental variation are predictable (i.e., seasonality), selection can favor some form of trait variation or associated strategy that enables flexibility (e.g., adaptive plasticity; Ghalambor et al. 2007, Shima et al. 2018).

Reproductive phenology is a particularly good example of this. Many organisms (e.g., plants [Wheeler et al. 2015], insects [Forrest and Thompson 2011], birds [Dunn and Winkler 1999], mammals [Middleton et al. 2013], amphibians [Gibbs and Breisch 2001], and marine fishes [Genner et al. 2010]) reproduce seasonally, and at times that are likely to increase lifetime expected reproductive success. For semelparous organisms (e.g., many annual plants, Pacific salmon), reproductive timing 
should be driven primarily by strategies that increase offspring success. For organisms that reproduce more than once, reproductive timing may reflect a compromise between strategies that increase the survival and expected reproductive success of individual offspring and those that increase adult survival and future reproduction (Warner 1998, Wadgymar et al. 2017).

Environmental predictability and the timescale of environmental changes can greatly influence patterns of reproduction. For example, many marine fishes exhibit seasonal reproduction in response to seasonal plankton blooms (i.e., larval food availability), with the degree of temporal concordance between spawning and food production affecting offspring survival (Cushing 1975, Beaugrand et al. 2003). Studies conducted at finer temporal scales demonstrate how "sweepstakes" events (e.g., disproportionate contributions from a small number of individuals or spawning bouts) may also be important in these systems (Hedgecock and Pudovkin 2011, Shima and Swearer 2016). The prevalence of sweepstakes recruitment suggests that environmental unpredictability may impede optimization of spawning times, and this may partly account for a preponderance of extreme iteroparity among many fishes (Johannes 1978, Claydon et al. 2014).

Coral reefs are less seasonal in terms of water temperature and pelagic larval food availability relative to habitats in higher latitudes. Nonetheless, important cyclic patterns may be imposed by the lunar cycle, which can synchronize reproductive activities (Foster et al. 2018), transport food, eggs, and/or larvae (via tides: Connell 1961, Sponaugle and Cowen 1996, Forward and Tankersley 2001), and affect the outcome of predator-prey interactions (via nocturnal illumination: Kronfeld-Schor et al. 2013, Prugh and Golden 2014, Palmer et al. 2017). Many coral reef fishes spawn at particular times of the lunar cycle (Johannes 1978, Claydon et al. 2014), and a given pattern of reproductive periodicity may maximize adult survival and/or offspring performance (Robertson et al. 1990). The larval stages of many of these species also settle back to the reef during particular moon stages; most commonly, settlement occurs at night, and close to the new moon (Dufour and Galzin 1993, Rankin and Sponaugle 2014, Shima et al. 2018). Settlement near the new moon is generally assumed to be an adaptation that reduces risk to nocturnally active predators that might derive a foraging advantage from moonlight (e.g., Acosta and Butler 1999).

Beyond noting these patterns and their effects on recruitment dynamics, few studies (but see Sponaugle and Cowen 1994, Robertson et al. 1999) have considered the implications of "lunar phenologies," which may impose compelling conflicts between strategies that benefit adults and those that benefit their offspring: lunar spawning patterns that maximize parent survival may differ from those that maximize offspring survival (Robertson et al. 1990, Shima et al. 2018). Moreover, few studies consider the broader implications of cyclical variation in nocturnal illumination, which has the potential to strongly shape the growth and survival of early life-history stages of reef fishes in the pelagic environment (Hernandez-Leon 2008, Shima and Swearer 2019).

Here we focus on a highly iteroparous coral reef fish, the sixbar wrasse (Thalassoma hardwicke). We compare lunar variation in reproductive output to birth dates of offspring that survive to settle back onto the reef (which we reconstruct from otolith microstructure). We estimate relative survival of offspring born across the lunar cycle to test the hypotheses that (1) survival varies as a function of lunar birth date and (2) offspring exhibit adaptive plasticity in development time (i.e., as predicted by Shima et al. 2018). More specifically, we predict that selection should favor birth dates and/or adjustments to larval developmental durations that facilitate settlement back to the reef on the new moon. Our results illustrate how an interaction among early life-history traitsspecifically, birth dates imposed by parents and plasticity in developmental duration by offspring - may drive phenotypic variation that shapes selection through to adulthood.

\section{Methods}

\section{Study system}

We estimated temporal variation in reproductive output, birth dates, and larval traits of recently settled sixbar wrasse (Thalassoma hardwicke) sampled from the northern lagoon of Moorea, French Polynesia. Sixbars are coral reef fish, commonly found on shallow fringing reefs and lagoons throughout much of the Indo-Pacific region. They are protogynous hermaphrodites, and spawn pelagic eggs at sites that are typically located at reef edges, near passes (i.e., gaps in a barrier reef crest). Spawning activity is generally greatest between 14:00 and 16:00 on Moorea, at times when offshore water flow is strongest (P. Mitterwallner, unpublished data). These spawning patterns may serve to maximize offshore transport of eggs (i.e., away from high concentrations of reefbased egg predators; Johannes 1978, Robertson et al. 1990).

Spawning occurs most days of the lunar cycle and throughout much of the year (Claydon et al. 2014). Larvae develop at sea for $\sim 7$ weeks (mean $=47 \mathrm{~d}$; range 39-63 d; Victor 1986a) and subsequently settle to patch reefs within the lagoons of Moorea (Shima 2001a). Settlement occurs at night (Dufour and Galzin 1993) and is greatest during nights close to the new moon. Larvae may be able to delay maturation to avoid settling during brighter periods of the lunar cycle and/or target predictably darker periods (Shima et al. 2018) when the effectiveness of nocturnal reef-based predators may be curtailed (Acosta and Butler 1999). Postsettlement mortality of young sixbars is strongly density dependent (Shima 2001b, Shima and Osenberg 2003), and is further mediated by priority effects (Geange and Stier 2009), as 
well as by interactions with other species (Shima 2001a, Shima et al. 2006, 2008, Geange et al. 2013).

\section{Estimating reproductive output across the lunar cycle}

Surveys of spawning. We surveyed spawning adults at the eastern edge of the Cook's Bay pass $\left(17^{\circ} 28.850^{\prime} \mathrm{S}\right.$, $\left.149^{\circ} 49.138^{\prime} \mathrm{W}\right)$ and the western edge of the Maharepa pass $\left(17^{\circ} 28.560^{\prime} \mathrm{S}, 149^{\circ} 47.985^{\prime} \mathrm{W}\right)$, on the northern shore of Moorea. Surveys were conducted 3-5 d per week, over 20 consecutive weeks (i.e., spanning lunar months from February to June 2017). Logistical constraints meant that we could only survey one location on a given day, and successive surveys typically alternated between locations. At both locations, we quantified spawning frequencies within the well-delineated boundaries of 2-3 territorial males. Each survey consisted of a 20-min observation period at each territory, during which a single observer (PM) recorded all pair spawning events (including those with males other than the territory holder) and estimated the size of each spawning female (total length [TL] to the nearest $10 \mathrm{~mm}$ ). Visual size estimates were routinely calibrated against objects of known size (i.e., lengths of PVC pipe suspended from small floats) placed in situ. All observations were made between 14:00 and 16:00, during times of peak spawning activity.

Relationship between gonad mass and fish length.-We collected a sample of $\sim 20$ adult sixbars at weekly intervals from February to June 2017. All fish were caught via hook and line from an area of fringing reef that was $\sim 5 \mathrm{~km}$ from surveyed spawning locations (and not in an area where fish routinely spawn). We recorded total length $(\mathrm{mm})$ and gonad wet mass $(\mathrm{g})$ of all females from this collection. We categorized each sampling date by lunar phase (i.e., new moon, first quarter, full moon, last quarter) and we explored variation in $\log _{10}$ (gonad mass) as a function of (1) $\log _{10}(\mathrm{TL})$, (2) lunar phase, and (3) an interaction between lunar phase and $\log _{10}(\mathrm{TL})$, using a general linear model (here and elsewhere: $1 \mathrm{~m}$ function [R Development Core Team 2019]; all effects evaluated with type III SS, car package for R [Fox and Weisberg 2019]). The relationship between $\log _{10}$ (gonad weight) and $\log _{10}(\mathrm{TL})$ was highly significant $\left(F_{1,130}=31.22\right.$, $P<0.0001)$ and was not affected by the lunar phase $\left(F_{3,130}=0.86, \quad P=0.46\right)$ or the interaction term $\left(F_{3,130}=0.91, P=0.44\right)$. This relationship was also strongly wedge shaped (suggesting asynchronous gonad development and/or spawning; i.e., some individuals of a given size had heavy gonads with well-developed oocytes, whereas others with light gonads appeared to have spawned recently). We therefore made two assumptions in characterizing the relationship between $\log _{10}$ (gonad weight) and $\log _{10}(\mathrm{TL})$ : (1) this relationship is invariant with respect to lunar phase (i.e., it can be described by a single function), and (2) the upper bound of the wedge-shaped distribution most accurately reflects the relationship between $\log _{10}$ (gonad mass) and $\log _{10}$ (TL) for spawning-stage (i.e., ripe) females. We used quantile regression to estimate parameters (slope and intercept) associated with this upper bound (tau $=0.95$, rq function of quantreg package, Koenker 2019).

Relative egg production.-We estimated relative egg production for days in which reproductive surveys were conducted using estimates of the number and sizes of spawning females at the focal territories at a given location on a given day, and the power function describing the upper quantile of the relationship between gonad mass and fish total length:

$$
\text { relative egg production }=\sum_{j=1}^{n} a L_{j}^{b}
$$

where $L_{j}$ is the total length of female $j, b$ is the scaling exponent (i.e., the slope of the relationship between $\log _{10}$ (gonad weight) and $\log _{10}(\mathrm{TL})$ from quantile regression, above), $a$ is the coefficient (i.e., the back-transformed intercept from quantile regression, above), and $n$ is the number of females that spawned on a given day. We standardized relative egg production by the number of territories observed (either two or three). We re-expressed each calendar date as a "lunar day" (i.e., where day 0 corresponds to the new moon, day 14 to the full moon, etc.), and a categorical variable describing the lunar month (i.e., the Brown lunation number). We binned lunar days (bin size $=2$ ) to increase the number of estimates of reproduction for each time step $(n=75$ observations, distributed among the two locations, 15 lunar bins, and six lunar months). Hereafter we refer to these binned records as lunar days. We first evaluated variation in egg production using a general linear model with linear and quadratic terms for lunar day (i.e., lunar day, lunar day ${ }^{2}$ ), and lunar month and location as blocking effects. The effect of lunar month was not significant $(P=0.33)$, so we did not include it in our final model (described in the following paragraph), which therefore expressed egg production across a typical lunar cycle for the two locations.

To facilitate comparisons with subsequent analyses (described below), we evaluated "proportional egg production" (i.e., the ratio of egg production during each lunar day to the summed egg production across all lunar days for each location) as our response variable $(n=27$ observations). We evaluated variation in proportional egg production using a general linear model with linear and quadratic terms for lunar day, and location as a blocking effect.

\section{Estimating the birth dates of settlers and surviving juveniles across the lunar cycle}

Sampling fish. We established eight sampling locations on the north shore of Moorea, stratified by long-shore 
and cross-shore environmental gradients (e.g., Shima 1999, Shima 2001a, Shima et al. 2008), and adjacent to the sites where we sampled reproductive output (VOE: 17²8.697' S, $149^{\circ} 50.425^{\prime} \mathrm{W}$; VME: 17²8.860' S, 149 $50.376^{\prime} \mathrm{W}$; VOW: $17^{\circ} 28.847^{\prime} \mathrm{S}, \quad 1^{\circ} 9^{\circ} 50.814^{\prime} \mathrm{W}$; VMW: $17^{\circ} 28.962^{\prime} \mathrm{S}, 149^{\circ} 50.748^{\prime} \mathrm{W}$; MOM: $17^{\circ} 28.522^{\prime} \mathrm{S}$, 14948.600' W; MMM: 17²8.612' S, 14948.559' W; TOM: $17^{\circ} 28.464^{\prime} \mathrm{S}, 149^{\circ} 47.424^{\prime} \mathrm{W}$; TMM: $17^{\circ} 28.567^{\prime} \mathrm{S}$, $149^{\circ} 47.439^{\prime} \mathrm{W}$; site abbreviations are a 3-letter acronym indicating lagoon name, cross-shore position and longshore position). Within each location, we selected 20 small focal patch reefs (mean surface area $=17.06 \mathrm{~m}^{2}$, $\mathrm{SD}=7.77 ; \min =5.83, \max =42.48)$ of variable composition (e.g., mean live coral cover $=13.99 \%, \mathrm{SD}=14.58$, $\min =0, \max =88)$. We quantified habitat attributes of each reef following methods of Shima et al. (2008). We visually estimated percent cover of substrate categories (Porites lobata, Porites rus, total live coral, algal turf associated with territorial damselfish [Stegastes nigricans], Turbinaria ornata, total macroalgae, and bare substrate [including crustose coralline algae]). We also estimated the total number of branching coral colonies (Pocillopora spp. and Acropora spp.), reef surface area (estimated from measurements of maximum length, maximum perpendicular width, and typical height, using the formula for surface area of a semiellipsoid), reef height, depth at reef base, and reef isolation (as the proportion of a 2-m halo around each reef that was occupied by adjacent patch reefs). We used these metrics in a clustering procedure (PROC CLUSTER, SASv9.4, Ward method) to identify reef pairs (based on multivariate similarity) within each of the eight sites. One reef in each pair was randomly assigned to be sampled repeatedly (i.e., to collect "settlers"), and the other reef from the pair was to be sampled only once at the end of the season (to collect "surviving juveniles"). This yielded a total of 80 reefs from which we collected settlers and 80 from which we collected surviving juveniles.

From one of these sets of reefs ( $n=80$ focal reefs, i.e., 10 reefs at each of eight sites), we collected all settlers (sixbars $<15 \mathrm{~mm}$ TL) at approximately weekly intervals for 16 consecutive weeks, from February to June 2017. All collections were made with hand nets aided by clove oil anesthetic. When fewer than 10 settlers were collected from the 10 focal reefs within a given site and week, we collected supplemental fish (of sizes suggesting recent settlement) from nearby reefs that were selected haphazardly. At the end of the sampling period (in June 2017), we collected all surviving juveniles (i.e., sixbars $<60 \mathrm{~mm}$ TL) from the remaining 80 focal reefs. These juveniles represent fish that had survived from settlement until being collected in June 2017. When fewer than 40 surviving juveniles were collected from the 10 focal reefs in a given location at the end of the season, we supplemented our samples with fish collected from nearby reefs that were selected haphazardly. In total, we collected 957 settlers $(31.0 \%$ of these from focal reefs, remainder from supplemental reefs) over the 16 weeks of sampling, and we collected 451 surviving juveniles from paired reefs at the end of the field season $\mathbf{7} 71.4 \%$ of these from focal reefs, remainder from supplemental reefs). We characterized birth dates and larval traits of (1) settlers and (2) surviving juveniles using otoliths from a subsample of these individuals (described below). We assumed that the two sets of focal reefs (i.e., distributed evenly across long-shore and cross-shore environmental gradients, and similar in size and composition) provided samples of the same cohorts of young fish, both at the start of and after an extended period of postsettlement mortality.

Birth dates of settlers and surviving juveniles. - We analyzed otolith microstructure for a subsample of 418 settlers ( $\sim 5$ settlers from each of the eight sites, from each week; selected randomly from available samples; $33.7 \%$ were from focal reefs) and 297 surviving juveniles ( 40 sixbars of mixed ages from each of the eight sites, collected at the end of the season; 74.5\% were from focal reefs). We extracted sagittal otoliths, cleaned them following methods of Shima and Swearer (2009), and sent them to CEAB's Otolith Research Lab, where they were mounted sulcus-side down and polished along the sagittal plane to expose daily growth increments (validated in Shima 1999) along the postrostral axis. Daily increment widths from the otolith core to the conspicuous settlement mark were tagged and measured along this axis using the caliper tool of ImagePro Premier.

We estimated each individual's larval age (i.e., pelagic larval duration, PLD, in days) from the number of tagged daily growth increments counted from the core to the settlement mark plus two (to account for the lag between spawning and the initiation of otolith increments: Victor $1986 a$ ). In addition, we estimated postsettlement age from the number of daily increments counted from the settlement mark to the otolith edge. We estimated the calendar date of an individual's birth by taking the known date of collection and subtracting the estimated age of the fish (i.e., number of larval increments $+2+$ number of postsettlement increments). For all subsequent analyses, we constrained our data to include only those fish with birth dates that fell within the range of our sampling of adult reproduction (giving final sample sizes: $n=292$ for settlers, $n=122$ for surviving juveniles).

As described in the section "Relative egg production", we re-expressed calendar dates of each individual's birth on a lunar calendar, binned these birth dates (bin size $=2$ ), and assigned these to a categorical lunar month (as described for the egg index, above). For each lunar month, we then calculated the proportion of fish that were born on a particular lunar day. We evaluated variation in proportions of births across lunar days using general linear models. Because relationships were curvilinear, we modeled proportional births as a function of lunar day and its quadratic term. We analyzed proportional births for settlers and for surviving juveniles in two separate models. 


\section{Selection on birth date during larval and juvenile stages}

A mother imposes consequences on her young, for example, through their birth dates. We evaluated the pattern of selection on birth dates by comparing relative survival through two key episodes in the life history of the fish: (1) from birth to settlement, and (2) from settlement until capture in June (i.e., during the postsettlement, juvenile phase). We quantified selection on fish born on different lunar days by comparing the distribution of birth dates of settlers (i.e., fish that survived to settlement) to the distribution of egg production, and by comparing the distribution of the birth dates of surviving juveniles to the distribution of birth dates of settlers. Here the pattern of selection (i.e., relative fitness during the focal episode) was estimated from the relationship between $\log _{10}\left(P_{j+1, i}\right)$ $\left.P_{j, i}\right)$, and birth date, where $P_{j, i}$ is the proportion of individuals in stage $j$ (eggs, settlers, or surviving juveniles) that were born on lunar day $i(n=15$ bins, between 0 and 30$)$, and proportions were extracted from the above analyses. Estimates greater than 0 indicate that fish born during that lunar day survived relatively well, whereas estimates $<0$ indicate relatively poor survival (i.e., fish born on those lunar days were selected against; see Manly 2013 for a discussion of indices of selection). We modeled selection as a function of lunar day and its quadratic term.

\section{Larval traits of settlers and surviving juveniles born on different lunar days}

Shifts in larval developmental duration. We estimated how much a given larval fish shifted its settlement date from its default date: that is, what was expected based upon its birth date and an average PLD of $47 \mathrm{~d}$ (Victor 1986a). Specifically, we (1) obtained the expected day of settlement (i.e., in the absence of plasticity) by adding 47 to the estimated birth date of each fish; (2) calculated the absolute value of the difference between the expected day of settlement and the actual day of settlement; (3) estimated lunar illumination (i.e., percent of lunar disc illuminated) https://www.timeanddate.com for each possible settlement day; and (4) assigned a negative sign to the absolute value of the difference in predicted and actual settlement dates (from step 2), when lunar illumination on the expected settlement day was less than illumination on the actual settlement day. This procedure yielded an estimate of the "developmental shift toward settlement on a darker (i.e., safer) night" for each individual. A positive value means that fish settled on a night that had less lunar illumination than on their expected settlement date (given their lunar birth date); a negative value means that a fish settled on a night with more moonlight (on average) than expected based on their birth date. Note that these shifts could occur either because a fish spent more or less time in the pelagic environment. We hypothesized that fish would alter their developmental durations to settle on darker (and therefore safer) nights.
Larval age and size at settlement.-We analyzed variation in larval age at settlement (PLD) and larval size at settlement of fish born on different lunar days using general linear models. We estimated size at settlement as the distance from the otolith core to the settlement mark, measured along the postrostral axis. Because relationships were curvilinear, we modeled response variables (i.e., age at settlement or size at settlement) as cubic polynomial functions of lunar day. We also included stage (either settler or surviving juvenile) in our models to test explicitly for a difference in intercept and interactions with polynomial terms, which would suggest directional selection during the benthic life phase.

\section{Postsettlement patterns of selection on age and size at settlement}

We estimated the selection differential on age and size at settlement across the juvenile stage for fish born on different lunar days. We calculated the selection differential for fish born on each lunar-day as the difference in mean age (or size) at settlement before vs. after selection (i.e., the selection differential, $S$, for fish born during lunar day $i$ is $S_{i}=Z_{\text {juveniles }, i}-Z_{\text {settlers, } i}$, where $Z$ is the mean age or size).

We also sampled adults concurrently with our collections of settlers and surviving juveniles (as part of our study of egg production, described above), and this enabled us to explore shifts in trait distributions through to adulthood. We analyzed otoliths from a subsample of these adults (187 fish: a stratified-random sample of $\sim 12$ fish per week, sampled over 16 weeks), and though we could not resolve total age in days (which would have enabled us to align life-history events to a lunar calendar), we successfully reconstructed the age at settlement and size at settlement for 170 individuals of this subsample (as described above for recently settled fish and older juveniles). We assumed that the reconstructed larval traits of these adults (spanning a wide range of ages and year classes) originated from a distribution of larval traits similar to our sample of settlers, but as modified by postsettlement processes. From these data, we inferred patterns of selection based on differences in (1) age at settlement and (2) size at settlement across ontogeny: that is, by comparing these traits in settlers, surviving juveniles, and adults. We analyzed age at settlement and size at settlement separately, using one-way ANOVAs to partition variation among settler, surviving juvenile, and adult age classes ( $1 \mathrm{~m}$ function, R Development Core Team 2019).

\section{RESULTS}

Variation in egg production and birth dates across the lunar cycle

Egg production by sixbars was greatest on the new moon, and minimal near the full moon (Fig. 1a). The 
temporal pattern of egg production did not vary between locations, so we dropped the blocking term for location and evaluated a reduced model that included only linear and quadratic terms for lunar day. The linear term for lunar day of birth was significant (parameter estimate $\left.=-0.012, F_{1,24}=5.32, P=0.03\right)$, as was the quadratic term (parameter estimate $=0.00042, F_{1,24}=$ 5.12, $P=0.033$ ), yielding the U-shaped pattern of egg production across the lunar cycle given in Fig. 1a.

In sharp contrast to patterns of egg production, significantly more sixbars surviving to settlement had birth dates that were closer to the full moon (Fig. 1b), when egg production was comparatively low (c.f. Fig. 1a). The blocking effect of lunar month was not significant in our full model, indicating that the temporal variation in birth dates of settlers was similar across lunar months, so we dropped lunar month as a blocking term and evaluated a reduced model that included only linear and quadratic terms for lunar day. The linear term for lunar day of birth was significant (parameter estimate $\left.=6.64 \times 10^{-03}, F_{1,57}=12.43, P=0.0008\right)$, as was the quadratic term (parameter estimate $=-3.03 \times 10^{-04}$ $\left.F_{1,57}=23.36, \quad P<0.0001\right)$, yielding the hump-shaped pattern of settler birth dates across the lunar cycle given in Fig. 1b. Higher proportions of settlers were born on the new moon (and days immediately following) than on the days just prior to the new moon (i.e., the hump was asymmetric).

Similarly, most surviving juveniles (i.e., fish that survived on reefs for up to several months after settlement) had birth dates that were closer to the full moon (Fig. 1c). Again, the blocking effect of lunar month was not significant in our full model, so we evaluated a reduced model that included only linear and quadratic terms for lunar day. The linear term for lunar day of birth was significant (parameter estimate $=6.47 \times 10^{-03}, F_{1,57}=5.98$, $P=0.018$ ), as was the quadratic term (parameter estimate $=-3.17 \times 10^{-04}, F_{1,57}=12.87, P=0.0007$ ), yielding the hump-shaped pattern of surviving juvenile birth dates across the lunar cycle given in Fig. 1c. Higher proportions of surviving juveniles were born on the new moon (and days immediately following) than on the days just prior to the new moon (i.e., the hump was asymmetric).

\section{Selection on birth dates during larval and juvenile stages}

The probability of survival from birth to settlement (i.e., during the larval stage) varied with birth date, with selection favoring fish born near the full moon (Fig. 2a). Survival through the pelagic larval stage increased from its smallest value for fish born shortly after the new moon and increased to its maximum for offspring spawned at (or just before) the full moon; survival then decreased again in the lead up to the next new moon; the rate of change in relative survival before and after the new moon was asymmetric. The linear term for lunar day of birth was significant (parameter estimate $=0.13$,
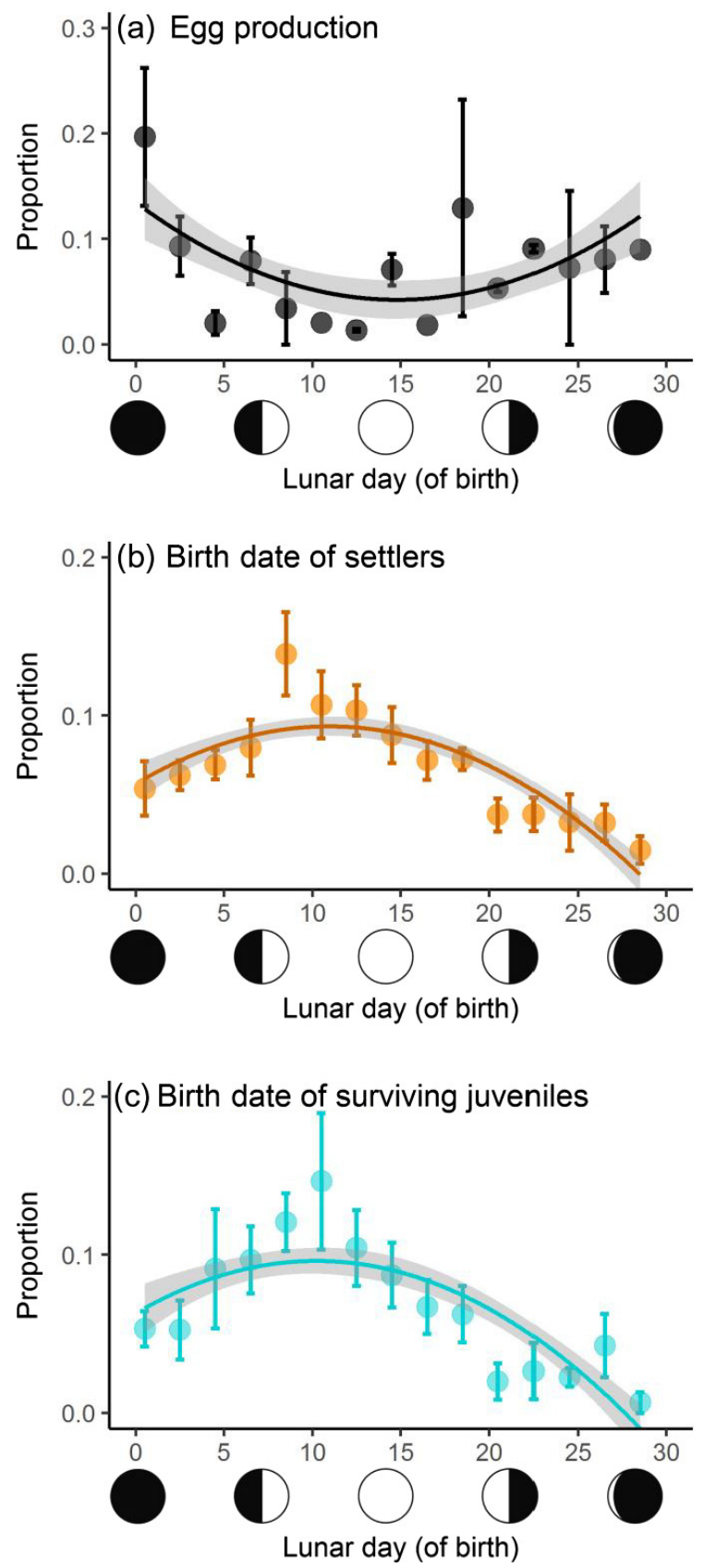

FIG. 1. Variation in (a) initial birth dates (i.e., daily egg production), (b) birth dates of settlers, and (c) birth dates of surviving juveniles of the sixbar wrasse. Calendar dates are expressed on a 29.5 -d lunar cycle where $0=$ new moon and $14=$ full moon; binned over 2-d intervals). Points and error bars give mean $\pm 1 \mathrm{SE}$ averaged across 4-5 lunar months). Fitted lines ( \pm 1 SE confidence envelope, shown in gray) are based on parameters estimated from a quadratic model.

$\left.F_{1,12}=11.61, P=0.005\right)$, as was the quadratic term (parameter estimate $=-0.005, F_{1,12}=17.38, P=0.0013$ ), yielding the hump-shaped pattern of selection on settler birth dates across the lunar cycle given in Fig. 2a. In 

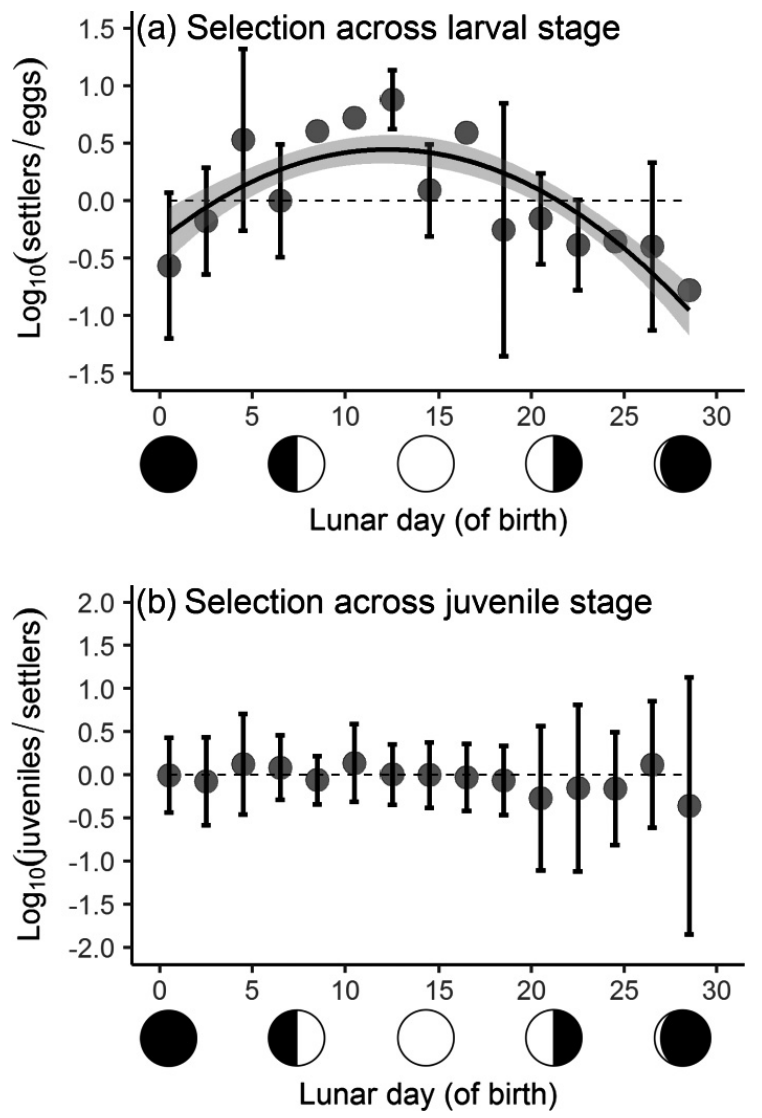

FIG. 2. Patterns of selection on birth date: (a) during the larval stage, (b) during the juvenile stage. Relative fitness for each time step is estimated from a log ratio of values given in Fig. 1; error bars give \pm 1 SE estimated by the Delta method. Dashed lines indicate no selection. Fitted line $( \pm 1$ SE confidence envelope) in (a) is based on parameters estimated from a quadratic model.

contrast, relative survival after settlement did not appear to vary with lunar birth date (Fig. 2b). Collectively, these patterns suggest that selection on birth dates acted primarily on fish during the larval stage.

\section{Plasticity in larval developmental duration: Do larvae adjust to settle on a darker night?}

Pelagic larval durations of settlers ranged from 37 to $61 \mathrm{~d}($ mean $=46.43, \mathrm{SD}=4.12)$, and these were similar to earlier reports of larval duration of sixbars sampled from other locations (c.f., mean PLD $=47$ d; range 39$63 \mathrm{~d}$; Victor 1986a). However, a histogram of our sample suggests a bimodal tendency, with modal developmental durations on either side of the $\sim 47-d$ mean (i.e., at 45 and $48 \mathrm{~d}$ [Fig. 3a]). Moreover, the distribution of developmental durations varied strongly with lunar day of birth (Fig. 3b). Fish born immediately after the new moon (i.e., left side of Fig. 3b) had longer developmental durations than other settlers (i.e., distributions of developmental duration were strongly right-skewed; c.f.,
Fig. 3a). In contrast, fish born around the full moon (middle region of Fig. 3b) had developmental durations that were approximately normally distributed around the mean larval duration. And fish born near that end of the lunar cycle (i.e., in the lead-up to the new moon, right side of Fig. 3b) typically had shorter developmental durations (though notably, also some of the longest; i.e., developmental durations of fish spawned just prior to the new moon were highly variable).

This plasticity in developmental duration enabled most fish to shift their settlement date to a darker portion of the lunar cycle (Fig. 3c). Fish born early in the lunar cycle shifted their settlement date by $\sim 6 \mathrm{~d}$ on average, to settle on a darker night (and they primarily achieved this with a longer developmental duration, c.f. Fig. 3b). Fish spawned late in the lunar cycle shifted by a similar amount ( $\sim 5 \mathrm{~d}$ on average) to settle on a darker night, but this was achieved mainly by shortening developmental duration (c.f. Fig. 3b). Fish spawned close to the full moon shifted development by $\sim 3 \mathrm{~d}$ on average, but, counter to our expectations, they settled on a brighter night than expected based on a 47-d developmental duration.

\section{Variation in larval age and size at settlement: fitness implications}

As a consequence of developmental plasticity, fish born close to the new moon were older (Fig. 4a) and larger (Fig. 4d) at settlement. A general linear model evaluating variation in age at settlement had significant interactions between stage (i.e., settlers vs. surviving juveniles) and polynomial terms in the model (stage * lunar day: $F_{1,642}=14.70, P=0.00014$; stage $*$ lunar day $^{2}: F_{1,642}=17.28, P<0.0001$; stage $*$ lunar day $^{3}$ : $\left.F_{1,642}=19.17, P<0.0001\right)$. Similarly, a general linear model evaluating variation in size at settlement had significant interactions between stage and polynomial terms (stage * lunar day: $F_{1,642}=14.70, P=0.0098$; stage * lunar day ${ }^{2}: F_{1,642}=8.75, P=0.0032$; stage $*$ lunar day $\left.{ }^{3}: F_{1,642}=9.72, P=0.0019\right)$. These results suggest that older and larger fish at settlement were generally favored, although the likelihood of survival varied in a complex way with lunar day and life stage (Fig. 4b, e). In general, likelihood of survival for older and larger individuals appeared to be greater if they were born between lunar day 5 and 12 (roughly corresponding to birth dates in the first-quarter lunar phase) and between lunar day 26 and 29 (roughly corresponding to birth dates just prior to the new moon).

Mean age at settlement and size at settlement increased with developmental stage (ANOVA: age at settlement: $F_{2,581}=34.17, P<0.0001$; size at settlement: $F_{2,581}=12.92, P<0.0001$; Fig. $\left.4 \mathrm{c}, \mathrm{f}\right)$. These changes in trait distributions with age were consistent with postsettlement selection favoring fish that settled older, and at larger sizes. Collectively, these patterns suggest that early-life-history traits (which are the product of birth 
(a) Variation in developmental

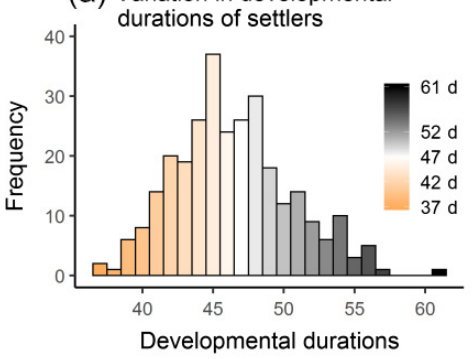

(b) Distribution of developmental

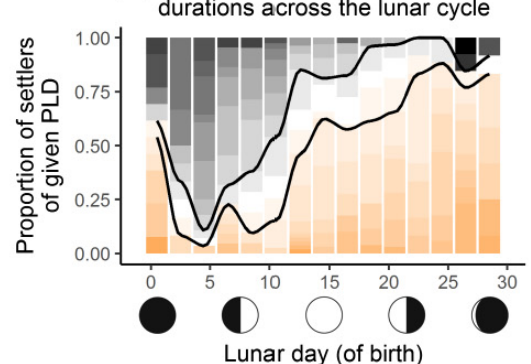

(c) Developmental shift to settle on a darker night

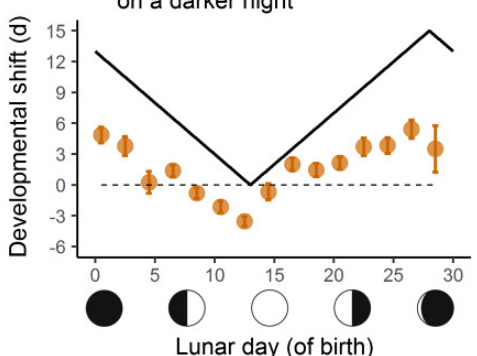

FIG. 3. Plasticity in developmental duration. (a) Histogram of pelagic larval durations of settlers (range: 37-61 d). (b) Distribution of developmental durations vary with lunar day of birth (see panel a for key; black lines bracket proportion of fish with average developmental duration (range: 46-48 d); orange gradient indicates fish with shortened development; black gradient indicates fish with extended development. (c) Shifts in larval developmental duration exhibited by fish born on different days of a lunar cycle. Developmental shift is a deviation (either positive or negative) from a default larval duration of $47 \mathrm{~d}$ (the mean pelagic larval duration [PLD] for sixbars) that facilitates settlement on a darker night of the lunar cycle. Given is the mean shift in days ( \pm 1 SE) for fish born on each lunar day (binned over 2-d intervals); values above zero (dashed line) indicate a shift toward a darker night of settlement. Solid black line indicates the minimum magnitude of developmental shift necessary to settle on the darkest night (i.e., a new moon).
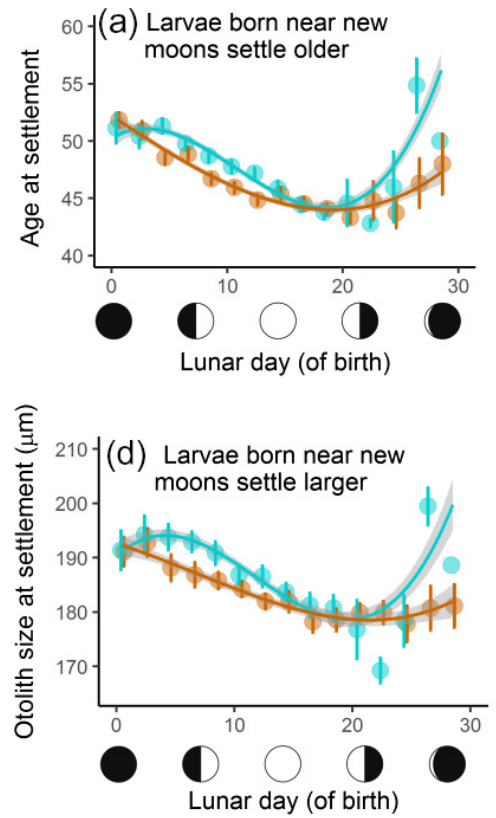
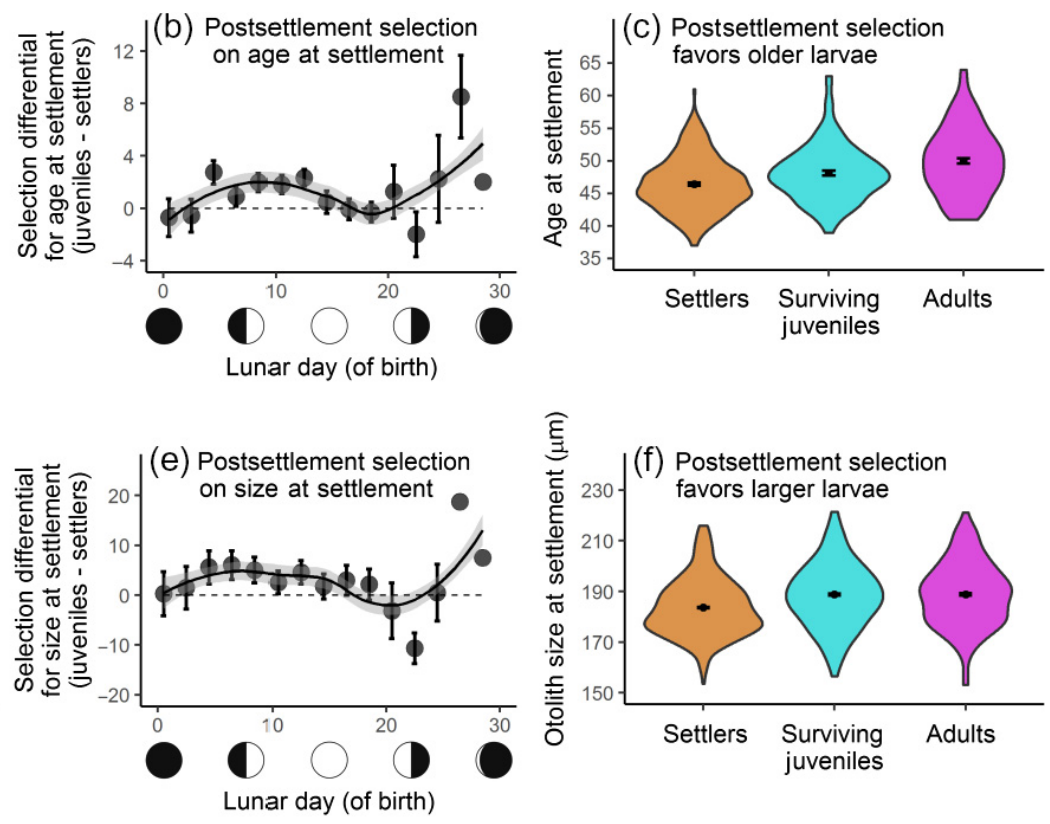

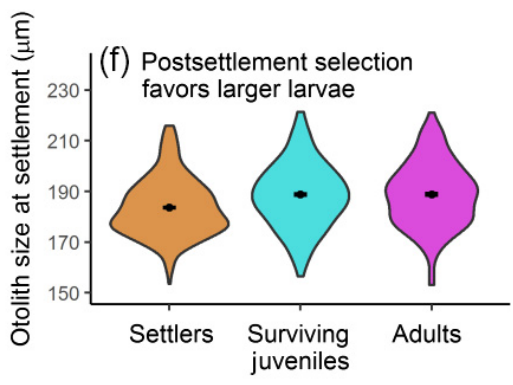

FIG. 4. Patterns of variation, and selection on larval age $(a-c)$ and size at settlement $(d-f)$ of fish born on different days of a lunar cycle. (a, d) Mean values of each trait $( \pm 1 \mathrm{SE})$ for settlers (orange) and surviving juveniles (turquoise). Fitted lines $( \pm 1 \mathrm{SE}$ confidence envelope, shown in gray) are based on parameters estimated from a polynomial model. (b, e) Selection differentials across the juvenile stage ( \pm 1 SE estimated by the Delta method); fitted line is a LOESS $( \pm 1 \mathrm{SE})$. (c, f) Variation in the distribution of traits across three age classes (settlers, surviving juveniles, and adults). Given are means (black dots, $\pm 1 \mathrm{SE}$ error bars) and the distributional summary illustrated with guitar plots.

dates imposed by parents and developmental durations modified by offspring) continue to shape patterns of selection through to adulthood.

\section{DisCUSSION}

Why do adults spawn most around the new moon (Fig. 1a), when at first glance, selection appears to strongly favor offspring that were born closer to the full moon (Fig. 1b, c, and Fig. 2a)? Part of the answer may lie in the developmental plasticity of offspring (Fig. 3a, b; see also Sponaugle and Cowen 1994, Shima et al. 2018). We suggest that plasticity in larval developmental duration has two important consequences for offspring survival (and, by extension, their own parents' reproductive success). (1) It empowers offspring with inauspicious birth dates to alter their own developmental trajectories, enabling them to settle on a darker night of the lunar 
cycle (Fig. 3c) when their odds of survival across a risky habitat transition might be increased (e.g., Shima et al. 2018). (2) These offspring that were born at seemingly inauspicious times (and that managed to survive by altering their developmental trajectory) are likely to settle at an older age and larger size (Fig. 4a, d) and at times when relatively few other sixbars are settling. As a result, density-dependent interactions should be weaker, which should facilitate postsettlement survival (Shima et al. 2018). This hypothesis of adaptive plasticity in developmental duration, and its beneficial effects on age and size at settlement, may reduce the fitness costs of spawning at times other than the full moon. Thus, adaptive plasticity likely facilitates the evolution of extreme iteroparity in sixbars through reciprocal dependencies between the strategies of parents and their offspring (Shima et al. 2018).

Although our data are completely consistent with adaptive plasticity in development time, we note that this hypothesis presupposes a set of unverified behavior patterns that would enable offspring to alter their own developmental trajectory actively in response to the lunar cycle. Given the range of behavior patterns documented for larval fishes (e.g., responses to sound [Simpson et al. 2005], chemical cues [Atema et al. 2002], light [Job and Bellwood 2000]), we do not believe this is overly speculative. However, we note that this potential mechanism of adaptive plasticity could also arise from differential egg provisioning across the lunar cycle (i.e., parents determine developmental durations of their offspring). Both mechanisms are likely to favor extreme iteroparity. Given that egg provisioning in sixbars is very low and largely invariant (Barneche et al. 2018), we suggest that differential maternal provisioning is an unlikely explanation for the observed patterns. A third hypothesis is that developmental durations vary randomly among individuals and through time, but these trajectories are otherwise inflexible within an individual. In this case, the patterns that we observed may simply reflect strong selective mortality on a fixed trait (i.e., there is no strategy on the part of parents or their offspring, and only those individuals with particular combinations of developmental duration and birth date survive to settlement). Because we can only evaluate the traits of survivors, we are unable to evaluate this alternative hypothesis. However, given the nature and strength selection differentials that we have estimated (and the fact that a cyclical pattern of nocturnal illumination has persisted largely unchanged across the evolutionary history of fishes), we think this is unlikely.

Adult sixbars may spawn near the new moon for other reasons (Robertson et al. 1990), and we note that none of these are mutually exclusive with our hypothesis of adaptive plasticity. For example, adults should spawn preferentially at times that minimize their own risk of mortality (Warner 1998). Risk for a diurnal spawner could vary across the lunar cycle if, for example, the feeding activities of its predators also vary on a lunar cycle. Another possibility is that multispecies aggregations of spawning fish could attract predators. We have observed many different species spawning at the same locations as our sixbar populations, and a number of small-bodied reef fishes (e.g., Acanthurus nigrofuscus and Chlorurus sordidus) form large spawning aggregations on full moons (P. Mitterwallner, unpublished data). If lunar-cyclic aggregations of other species increase risk to spawning sixbars (via predator attraction), then this could provide another explanation for why sixbar spawning activity is reduced around the full moon.

Additionally, the timing of adult spawning might maximize fitness of offspring in ways other than simply enabling them to settle back to the reef at a good time (i.e., under cover of darkness). For example, spawning near the new moon may reduce risk to pelagic eggs in the first nights after spawning (i.e., when eggs may still be vulnerable to reef-based, nocturnally active egg predators). Furthermore, if we consider a more holistic view of how the lunar cycle might affect the fitness of early life-history stages from spawning to settlement, then additional selection pressures become apparent. Recent observations (Hernandez-Leon 2008, Shima and Swearer 2019) suggest that moonlight may reduce risk and increase reward to larval fishes in the pelagic habitat (i.e., moonlight at sea increases fitness) - in sharp contrast to its presumed effects on/near the reef (where moonlight increases risk to nocturnally active predators). This is because moonlight in the pelagic habitat may simultaneously increase foraging opportunities for larval fishes (because they can see their prey at night) and reduce the densities of their predators (because the nocturnal activities of mesopelagic predators are suppressed by moonlight because of their vulnerability to their predators; Benoit-Bird et al. 2009, Drazen et al. 2011, Last et al. 2016, Prihartato et al. 2016). Under this scenario of a moonlight-mediated trophic cascade, adult sixbars that spawn on a new moon may enable their offspring to capitalize on two of these favorable periods of bright nights to maximize growth and survivorship in the pelagic environment (i.e., at age 14 and $44 \mathrm{~d}$ ), and still depart and return to the reef under cover of darkness (i.e., recently spawned eggs transition to the pelagic on a dark night; late-stage larvae with plastic developmental durations can adjust PLD to settle on a darker night, or in a portion of the night that is dark, as discussed in a subseqnent paragraph of this section). Spawning at other times may negatively affect larval survival in the pelagic environment.

One interpretation of our data is that offspring may actively shape their own destiny from a very early age. Developmental durations (PLDs) are variable (Fig. 3a, indicating plasticity), and their distributions depend strongly on date of birth (Fig. 3b). Offspring systematically shorten or extend their PLDs to arrive back to the reef on particular nights that, for the most part, are (on average) darker than the ones predicted by a 47-d PLD. These observations are consistent with a hypothesis of 
adaptive plasticity in PLD, and similar patterns have been noted for the bluehead wrasse (Robertson et al. 1999). Though the developmental shifts of larval sixbars are generally in the direction of the darkest night of the lunar cycle (i.e., the new moon, indicated by the solid black line in Fig. 3c), they rarely enable larvae to achieve this presumed optimum. This may suggest physiological costs (or some other constraint) on the magnitude of a shift in PLD.

Growth rate during the larval stage can affect PLD. Faster-growing larvae often have shorter a PLD (e.g., Searcy and Sponaugle 2000, Sponaugle et al. 2006, Shima and Swearer 2009), and older larvae may stop growing (Victor 1986b). Larval growth rate also can vary seasonally (Grorud-Colvert and Sponaugle 2011, Rankin and Sponaugle 2011). Sponaugle and Pinkard (2004) examined settlement in relation to larval growth, oceanographic conditions, and lunar phase for the congener Thalassoma bifasciatum. Intriguingly, their work suggests that offspring born on different phases of the moon vary in their larval growth patterns, and that pelagic larval growth may accelerate close to the full moon irrespective of birth date (Sponaugle and Pinkard 2004: Fig. 6a; see also Shima and Swearer 2019). Collectively, these observations suggest that growth varies across the lunar month, that there is a minimum size at which larvae can settle, and that there are costs associated with getting too large. All of these factors should place limits on the degree to which fish can adjust their PLD in response to being born at the wrong time.

Interestingly, our data suggest that sixbars spawned just prior to the full moon tend to settle $\sim 3 \mathrm{~d}$ early (relative to a mean 47-d PLD), and that this systematic shift means that those individuals settle on a seemingly brighter night. One potential explanation for this pattern is that it is actually not more risky for the portion of the night when most fish are settling. For offspring born between day 10 and 13 of the lunar cycle, a shortened PLD results in settlement on a waning moon phase (i.e., just before a new moon) - and during this portion of the lunar cycle, the moon rises above the horizon progressively later after midnight. Most reef fishes on Moorea settle in the first half of the night (i.e., before midnight; Dufour and Galzin 1993), so there may be little added cost to settling on a brighter night between the third quarter and the new moon (because the moon has not yet risen when fish are transiting the reef crest and incurring risk; see also Sponaugle and Cowen 1994). The delayed moonrise associated with a waning moon might also increase the risks associated with the pelagic habitat (because nocturnal mesopelagic predator densities may not be suppressed for an increasing proportion of the night), and the antagonistic effects of moonlight on predation risk in pelagic and benthic habitats might alter $\mu$ / g differentials (sensu Werner and Gilliam 1984) to select for an earlier settlement date. In other words, a progressively later moonrise from third-quarter lunar phase (moonrise is after midnight starting at day 21) to the new moon makes remaining in the pelagic environment increasingly risky for a larval sixbar. The timing of moonrise (e.g., qualitative differences between first- and third-quarter lunar phases in the distribution of moonlight across nights, despite having the same average "lunar illumination") may account for the asymmetries in many of our plots (e.g., Figs. 1b, c, 2a, 3c, 4a, d). Alternatively, such asymmetries could arise from variation in nocturnal brightness relative to the timing of flood/ebb tides across the lunar cycle (e.g., Reyns and Sponaugle 1999, D’Alessandro, Sponaugle, and Lee 2007). We note, however, that the effects of tides on circulation and transport processes are relatively weak in our study system (Hench et al. 2008).

Collectively, these results suggest that larval fish have the behavioral and physiological capacity to settle at the first good opportunity, and that settlement might reasonably occur when localized nocturnal cloud cover effectively masks lunar illumination. This presupposes that larvae have the necessary sensory capabilities to detect changes in nocturnal lunar illumination, and that they are close enough in proximity to the reef to respond quickly. Variation in cloud cover could thus be an explanation for seemingly stochastic settlement of larval fish (or for settlement at anomalous times). A stochastic component of nocturnal lunar illumination afforded by nocturnal cloud cover could also drive the evolution of extreme iteroparity of sixbars, as a diversified bet-hedging strategy (Wilbur and Rudolf 2006).

Postsettlement selection on birth dates, per se, does not appear to be strong (Fig. 2b). However, our analyses suggest that birth dates may drive the developmental decisions of offspring, such that two outcomes of variable birth dates and adaptive developmental plasticity are lunar-cyclic variation in: (1) the phenotypes of settlers (i.e., age and size at settlement; Fig. 4a, d), and (2) the environmental conditions that offspring may encounter (e.g., priority effects, density dependence, and lunar-cyclic effects) in the benthic stage. Selection in the postsettlement stage favors larger and older individuals (Fig. 4c, f). However, these advantages accrue only to fish born between lunar day 5 and 12 (i.e., birth dates in the first-quarter lunar phase) and between lunar day 26 and 29 (i.e., birth dates just prior to the new moon). This implies that selection differentials on PLD may vary through time (e.g., Rankin and Sponaugle 2014). We suggest that an interaction between phenotypes and environmental conditions can account for these temporally varying selection differentials. Specifically, offspring spawned between lunar days 5 and 12 are predicted to settle $47 \mathrm{~d}$ later, between lunar days 22 and 29 (i.e., just prior to the new moon). This schedule is modified by the developmental delay, such that many of these individuals will arrive during a settlement pulse (i.e., a period of maximal settlement intensity). Postsettlement selection differentials evident in these birth date cohorts are consistent with higher lifetime expected fitness accruing to individuals that extended their 
developmental duration to settle older and larger (although we reiterate that part of this inference is based on a cross-sectional approach - settlers and juveniles are from different cohorts than are adults). In this instance, size- and age-related advantages appear to accrue during peak settlement events (Shima et al. 2018), when density-dependent mortality is likely to be highest (Shima 2001b).

In contrast, offspring spawned between lunar days 22 and 29 may accrue size and age-related advantages by a different mechanism. These individuals are predicted to settle $47 \mathrm{~d}$ later, between lunar days 14 and 17 (i.e., during brighter nights of the lunar cycle). To avoid settling on a bright night, offspring spawned at these times may either shorten their developmental durations to settle before the full moon $(\sim 75 \%$ of individuals appear to do this; Fig. 3b), or else they may extend their developmental durations to delay settlement until after the full moon ( $\sim 20 \%$ of individuals appear to do this; Fig. 3b). Postsettlement selection differentials evident in these birth date cohorts are consistent with higher fitness accruing to individuals that extended their developmental duration to settle after the full moon. In this instance, size- and agerelated advantages appear to accrue to older and larger individuals that also settled ahead of the following newmoon settlement pulse (i.e., these individuals likely benefit from settling older and larger, at lower densities, and with a priority effect). Given the apparent advantages associated with extended larval development, it is surprising that most fish appear not to do it. This may suggest additional risks associated with remaining in the pelagic habitat (or rewards of settling early) that are not fully captured in our data set (e.g., Werner and Gilliam 1984).

\section{ConClusion}

Moonlight drives a dynamic landscape of risk and reward for a wide range of organisms (Kronfeld-Schor et al. 2013, Prugh and Golden 2014, Palmer et al. 2017). The moon plays a particularly strong role in the ocean, where it synchronizes reproduction (Foster et al. 2018), mediates the tidal delivery of resources and propagules (Connell 1961, Sponaugle and Cowen 1996, Forward and Tankersley 2001), and suppresses nightly mass migrations of the most numerous vertebrate predators on Earth (Benoit-Bird et al. 2009, Drazen et al. 2011, Last et al. 2016, Prihartato et al. 2016). Lunar-mediated processes likely determine productivity, resilience, and community structure of many reef ecosystems. Our work suggests that moonlight may shape environmental variation and drive the evolution of fundamental life-history strategies in marine systems. In the case of the sixbar wrasse, moonlight-mediated effects may drive extreme iteroparity and adaptive plasticity in developmental duration. These effects further shape the phenotypes upon which selection operates, to reinforce particular life-history strategies via ecoevolutionary feedbacks between parental and offspring strategies.

\section{ACKNOWLEDGMENTS}

P. Caie, K. Hillyer, D. McNaughtan, and J. You-Sing assisted with sample collection, otolith extraction, and/or processing. N. Raventos (CEAB Otolith Research Lab) quantified otolith microstructure. O. Ronce facilitated access to sabbatical workspace and facilities at the Institut des Sciences de l'Evolution de Montpellier for JSS, and also provided useful discussion. S. Sponaugle and an anonymous reviewer provided thoughtful comments that improved this paper. Research grants from the Royal Society of New Zealand Marsden Fund (VUW1503, 2016-2020), the U.S. National Science Foundation (OCE- 1130359), and Victoria University of Wellington provided funding. Victoria University Coastal Ecology Lab and the UC Gump Research Station provided essential logistic support.

\section{Literature Cited}

Acosta, C. A., and M. J. Butler. 1999. Adaptive strategies that reduce predation on Caribbean spiny lobster postlarvae during onshore transport. Limnology and Oceanography 44:494-501.

Atema, J., M. J. Kingsford, and G. Gerlach. 2002. Larval reef fish could use odour for detection, retention and orientation to reefs. Marine Ecology Progress Series 241:151-160.

Barneche, D. R., D. R. Roberston, C. R. White, and D. J. Marshall. 2018. Fish reproductive-energy output increases disproportionately with body size. Science 360:642-645.

Beaugrand, G., K. M. Brander, J. A. Lindley, S. Souissi, and P. C. Reid. 2003. Plankton effect on cod recruitment in the North Sea. Nature 426:661-664.

Benoit-Bird, K. J., W. W. L. Au, and D. W. Wisdom. 2009. Nocturnal light and lunar cycle effects on diel migration of micronekton. Limnology and Oceanography 54:1789-1800.

Claydon, J. A. B., M. I. McCormick, and G. P. Jones. 2014. Multispecies spawning sites for fishes on a low-latitude coral reef: spatial and temporal patterns. Journal of Fish Biology 84:1136-1163.

Connell, J. H. 1961. Influence of interspecific competition and other factors on distribution of barnacle Chthamalus stellatus. Ecology 42:710-723.

Cushing, D. H. 1975. Marine ecology and fisheries. Cambridge University Press, Cambridge, UK.

D'Alessandro, E., S. Sponaugle, and T. Lee. 2007. Patterns and processes of larval fish supply to the coral reefs of the upper Florida Keys. Marine Ecology Progress Series 331:85-100.

Drazen, J. C., L. G. DeForest, and R. Domokos. 2011. Micronekton abundance and biomass in Hawaiian waters as influenced by seamounts, eddies, and the moon. Deep Sea Research 1:557-566.

Dufour, V., and R. Galzin. 1993. Colonization patterns of reef fish larvae to the lagoon at Moorea Island, French Polynesia. Marine Ecology Progress Series 102:143-152.

Dunn, P. O., and D. W. Winkler. 1999. Climate change has affected the breeding date of tree swallows throughout North America. Proceedings of the Royal Society B 266:2487-2490.

Forrest, J. R. K., and J. D. Thomson. 2011. An examination of synchrony between insect emergence and flowering in Rocky Mountain meadows. Ecological Monographs 81:469-491.

Forward R. B. Jr. and R. A. Tankersley. 2001. Selective tidalstream transport of marine animals. Oceanography and Marine Biology: An Annual Review 39:305-353.

Foster, T., A. J. Heyward, and J. P. Gilmour. 2018. Split spawning realigns coral reproduction with optimal environmental windows. Nature Communications 9:718. 
Fox, J., and S. Weisberg. 2019. An R companion to applied regression. Third edition. Sage, Thousand Oaks, California, USA. https://socialsciences.mcmaster.ca/jfox/Books/Compan ion/

Fretwell, J. R. 1972. Populations in a seasonal environment. Princeton University Press, Princeton, New Jersey, USA.

Geange, S. W., and A. C. Stier. 2009. Order of arrival affects competition in two reef fishes. Ecology 90:2868-2878.

Geange, S. W., A. C. Stier, and J. S. Shima. 2013. Competitive hierarchies among three species of juvenile coral reef fishes. Marine Ecology Progress Series 472:239-248.

Genner, M. J., N. C. Halliday, S. D. Simpson, A. J. Southward, S. J. Hawkins, and D. W. Sims. 2010. Temperature-driven phenological changes within a marine larval fish assemblage. Journal of Plankton Research 32:699-708.

Ghalambor, C. K., J. K. McKay, S. P. Carroll, and D. N Reznick. 2007. Adaptive versus non-adaptive phenotypic plasticity and the potential for contemporary adaptation in new environments. Functional Ecology 21:394-407.

Gibbs, J. P., and A. R. Breisch. 2001. Climate warming and calling phenology of frogs near Ithaca, New York, 1900-1999. Conservation Biology 15:1175-1178.

Grorud-Colvert, K., and S. Sponaugle. 2011. Variability in water temperature affects trait-mediated survival of a newly settled coral reef fish. Oecologia 165:675-686.

Hedgecock, D., and A. I. Pudovkin. 2011. Sweepstakes reproductive success in highly fecund marine fish and shellfish: a review and commentary. Bulletin of Marine Science 87: 971-1002.

Hench, J. L., J. J. Leichter, and S. G. Monismith. 2008. Episodic circulation and exchange in a wave-driven coral reef and lagoon system. Limnology and Oceanography 53:2681-2694.

Hernandez-Leon, S. 2008. Natural variability of fisheries and lunar illumination: a hypothesis. Fish and Fisheries 9:138 154.

Job, S. D., and D. R. Bellwood. 2000. Light sensitivity in larval fishes: Implications for vertical zonation in the pelagic zone. Limnology and Oceanography 45:362-371.

Johannes, R. E. 1978. Reproductive strategies of coastal marine fishes in the tropics. Environmental Biology of Fishes 3: 65-84.

Koenker, R.2019. Quantreg: Quantile Regression. \{R package version 5.51$\}$. https://CRAN.R-project.org/package=quantreg

Kronfeld-Schor, N., D. Dominoni, H. de la Iglesia, O. Levy, E. D. Herzog, T. Dayan, and C. Helfrich-Forster. 2013. Chronobiology by moonlight. Proceedings of the Royal Society B 280:20123088.

Last, K. S., L. Hobbs, J. Berge, A. S. Brierley, and F. Cottier. 2016. Moonlight drives ocean-scale mass vertical migration of zooplankton during the Arctic winter. Current Biology 26:244-251

Manly, B. F. J. 2013. The statistics of natural selection. Chapman and Hall, London, UK.

Middleton, A. D., M. J. Kauffman, D. E. McWhirter, J. G. Cook, R. C. Cook, A. A. Nelson, M. D. Jimenez, and R. W. Klaver. 2013. Animal migration amid shifting patterns of phenology and predation: lessons from a Yellowstone elk herd. Ecology 94:1245-1256.

Palmer, M. S., J. Fieberg, A. Swanson, M. Kosmala, and C. Packer. 2017. A 'dynamic' landscape of fear: prey responses to spatiotemporal variations in predation risk across the lunar cycle. Ecology Letters 20:1364-1373.

Prihartato, P. K., X. Irigoien, M. G. Genton, and S. Kaartvedt. 2016. Global effects of moon phase on nocturnal acoustic scattering layers. Marine Ecology Progress Series 544:65-75.

Prugh, L. R., and C. D. Golden. 2014. Does moonlight increase predation risk? Meta-analysis reveals divergent responses of nocturnal mammals to lunar cycles. Journal of Animal Ecology 83:504-514.

R Development Core Team. 2019. R: A language and environment for statistical computing. R Foundation for Statistical Computing, Vienna, Austria. https://www.R-project.org/

Rankin, T. L., and S. Sponaugle. 2011. Temperature influences selective mortality during the early life stages of a coral reef fish. PLoS ONE 6:e16814.

Rankin, T. L., and S. Sponaugle. 2014. Characteristics of settling coral reef fish are related to recruitment timing and success. PLoS ONE 9:e108871.

Reid, J. M., J. M. J. Travis, F. Daunt, S. J. Burthe, S. Wanless, and C. Dytham. 2018. Population and evolutionary dynamics in spatially structured seasonally varying environments. Biological Reviews 93:1578-1603.

Reyns, N., and S. Sponaugle. 1999. Patterns and processes of brachyuran crab settlement to Caribbean coral reefs. Marine Ecology Progress Series 185:155-170.

Robertson, D. R., C. W. Petersen, and J. D. Brawn. 1990. Lunar reproductive cycles of benthic-brooding reef fishes: reflections of larval biology or adult biology. Ecological Monographs 60:311-329.

Robertson, D. R., S. E. Swearer, K. Kaufmann, and E. B. Brothers. 1999. Settlement vs. environmental dynamics in a pelagic-spawning reef fish at Caribbean Panama. Ecological Monographs 69:195-218.

Searcy, S. P., and S. Sponaugle. 2000. Variable larval growth in a coral reef fish. Marine Ecology Progress Series 206:213-226.

Shima, J. S. 1999. Variability in relative importance of determinants of reef fish recruitment. Ecology Letters 2:304-310.

Shima, J. S. 2001a. Recruitment of a coral reef fish: roles of settlement, habitat, and postsettlement losses. Ecology 82: 2190-2199.

Shima, J. S. 2001b. Regulation of local populations of a coral reef fish via joint effects of density- and number-dependent mortality. Oecologia 126:58-65.

Shima, J. S., E. G. Noonburg, S. E. Swearer, S. A. Alonzo, and C. W. Osenberg. 2018. Born at the right time? A conceptual framework linking reproduction, development, and settlement in reef fish. Ecology 99:116-126.

Shima, J. S., and C. W. Osenberg. 2003. Cryptic density dependence: effects of spatio-temporal covariation between density and site quality in reef fish. Ecology 84:46-52.

Shima, J. S., C. W. Osenberg, and C. M. St Mary. 2008. Quantifying site quality in a heterogeneous landscape: recruitment of a reef fish. Ecology 89:86-94.

Shima, J. S., C. W. Osenberg, C. M. St. Mary, and L. Rogers. 2006. Implication of changing coral communities: do larval traits or habitat features drive variation in density-dependent mortality and recruitment of juvenile reef fish? Pages 226-231 in Proceedings of the 10th International Coral Reef Symposium, Okinawa, Japan. http://www.reefbase.org/resource_ce nter/publication/icrs.aspx

Shima, J. S., and S. E. Swearer. 2009. Larval quality is shaped by matrix effects: implications for connectivity in a marine metapopulation. Ecology 90:1255-1267.

Shima, J. S., and S. E. Swearer. 2016. Evidence and population consequences of shared larval dispersal histories in a marine fish. Ecology 97:25-31.

Shima, J. S., and S. E. Swearer. 2019. Moonlight enhances growth in larval fish. Ecology 100:e02563.

Simpson, D. D., M. Meekan, J. Montgomery, R. McCauley, and A. Jeffs. 2005. Homeward sound. Science 308:221.

Sponaugle, S., and R. K. Cowen. 1994. Larval durations and recruitment patterns of two Caribbean gobies (Gobiidae): contrasting early life histories in demersal spawners. Marine Biology 120:133-143. 
Sponaugle, S., and R. K. Cowen. 1996. Nearshore patterns of coral reef fish larval supply to Barbados, West Indies. Marine Ecology Progress Series 133:13-28.

Sponaugle, S., K. Grorud-Colvert, and D. Pinkard. 2006. Temperature-mediated variation in early life history traits and recruitment success of the coral reef fish Thalassoma bifasciatum in the Florida Keys. Marine Ecology Progress Series 308:1-15.

Sponaugle, S., and D. Pinkard. 2004. Lunar cyclic population replenishment of a coral reef fish: shifting patterns following oceanic events. Marine Ecology Progress Series 267: 267-280.

Thomas, D. W., J. Blondel, P. Perret, M. M. Lambrechts, and J. R. Speakman. 2001. Energetic and fitness costs of mismatching resource supply and demand in seasonally breeding birds. Science 291:2598-2600.

Victor, B. C. 1986a. Duration of the planktonic larval stage of one hundred species of Pacific and Atlantic wrasses (family Labridae). Marine Biology 90:317-326.
Victor, B. C. 1986b. Delayed metamorphosis with reduced larval growth in a coral reef fish (Thalassoma bifasciatum). Canadian Journal of Fisheries and Aquatic Sciences 43:1208-1213.

Wadgymar, S. M., S. C. Daws, and J. T. Anderson. 2017. Integrating viability and fecundity selection to illuminate the adaptive nature of genetic clines. Evolution Letters 1:26-39.

Warner, R. R. 1998. The role of extreme iteroparity and risk avoidance in the evolution of mating systems. Journal of Fish Biology 53:82-93.

Werner, E. E., and J. F. Gilliam. 1984. The ontogenetic niche and species interactions in size-structured populations. Annual Review of Ecology and Systematics. 15:393-425.

Wheeler, H. C., T. T. Hoye, N. M. Schmidt, J. C. Svenning, and M. C. Forchhammer. 2015. Phenological mismatch with abiotic conditions-implications for flowering in Arctic plants. Ecology 96:775-787.

Wilbur, H. M., and V. H. F. Rudolf. 2006. Life-history evolution in uncertain environments: Bet hedging in time. American Naturalist 168:398-411. 